\title{
Optimum Network of Battery Storage to Support Electric Vehicle Charging Infrastructure in Smart Cities
}

\author{
Dong Zhao \\ Michigan State University \\ dzhao@msu.edu
}

\author{
Navwant Thakur \\ Michigan State University \\ thakurna@msu.edu
}

\author{
Jiayu Chen \\ City University of Hong Kong \\ jiaychen@cityu.edu.hk
}

\begin{abstract}
Smart mobility and transportation is a critical component of smart cities. One barrier to the smart transportation is a lack of charging stations that can empower a huge amount of electric vehicles, especially autonomous ones. Battery storage technology provides a buffer to a charging station network; however, how battery storage can serve a crucial role in enabling fast-charging stations to fulfill customer demand and providing a profit for charging station operators is unclear. This paper reports a discrete event simulation model to determine the optimum network of battery storage system including the battery type, size, and exchange range, considering construction costs. A case study of Detroit Area in the State of Michigan is provided to demonstrate the usage of the model. Results show that a small number but big size of battery units is optimal. Findings suggest that a condensed network of charging stations benefits more through battery units connected to a microgrid network. The work provides a decision support for planners, designers, and engineers to design and build battery storage systems in smart cities.
\end{abstract}

\section{Introduction}

Smart cities and infrastructure represent the future of urban development. The concept of smart cities becomes increasingly popular in literature and policies since the 1990s [1,2]. As a critical component of smart city, smart mobility allows urban resources to achieve efficient mobility and economic advantages. Electric vehicles (EVs) including autonomous ones will be a significant part of smart transportation in future urban systems. In addition, greater adoption of EVs may help address climate change and bring energy savings. The EVs include hybrid EVs (HEVs), plug-in hybrid EVs (PHEVs), and battery EVs (BEVs). According to the Electric Drive Transportation Association, EV sales in the United States jumped by $37 \%$ in 2016 with a total sale of 159,139 vehicles [3]. To address this trend, the U.S. government has pledged $\$ 22$ million to accelerate the development of plug-in EVs (PEVs) [4].

However, one critical barrier to the smart mobility is the shortage of infrastructure to support the growth of EVs, particularly a lack of charging stations that can empower a large amount of EVs. An energy gap often exists between energy supplied by the electric grids and the expected demand for a charging station during peak hours [5]. In such a case, EV users have to wait for a long time to fully charge their cars as less energy can be supplied. This problem even occurs when a charging station is functionally capable of the energy supply to its maximum rated value.

Advances in battery storage technology provide an opportunity to address the barrier to the shortage of charging stations; however, the planning decision to layout the battery storage in an EV charging station network is not clear to ensure optimum functional and economic performance. Of great interest to charging station operators and electric utilities is how charging infrastructure with insufficient energy supply can take advantage of stored energy from batteries to bridge the energy supply gap. In other words, the design and construction of battery storage units turn to a key for charging station networks to address the energy supply shortage and to meet the increasing demand from EVs.

Therefore, the overall goal of this work is to develop a discrete event simulation model that can determine the features of a battery storage system to support a given network of charging stations. The features of a battery storage system include battery type, battery size, and the number of batteries. In a construction management perspective, the work addresses two specific research questions: (1) What are the optimum battery type, battery size, and the number of battery units in a battery storage system that minimizes the construction cost of the charging station network and satisfies the energy load to the grid? (2) What are the favorable factors that are critical to the improvement of planning and design for EV charging station networks? 


\section{Background}

\subsection{Smart Mobility}

A variety of researchers identify the components of a smart city, for example, the economy, environment, governance, infrastructure, and the quality of life [6]. Fernandez-Anez, et al. [7] defines a smart city using six components which are the smart governance, smart economy, smart people, smart mobility, smart environment, and smart living. Smart mobility plays a vital role and directly or indirectly contributes to a smart city's other five components. The smart mobility provides an efficient and effective public transportation network to residents and ensures they are satisfied with the quality and accessibility of public transportation.

Smart cities highlight smart mobility as a strategy which shed light on EVs. EVs are expected to be the vehicles of future and many companies are involved in research and development of EVs. Companies also attempt to produce EVs to be driverless in order to increase their competitiveness. According to Lane, et al. [8], governments have two motivations to encourage the use of EVs, which are "risk management" and "industrial policy." Risk management relies on the perception that EVs represent an opportunity to decrease the adverse effects of oil dependence. Industrial policy explains that EV technology can create innovative manufacturing industries for governments and improve the economy by improving one or more industrial sectors. To sustain a strong economy, the opening of new business areas, innovation, and new technologies are needed [6].

EVs contribute to multiple components of a smart city except smart mobility. For example, EV industry creates new employment positions and leads to promising economic growth for the smart economy [5]. As an emerging area, the EV industry is responsible for the creation of many sub-sectors leading to innovations and inventions. The EV industry also influences the expansion of sub-sectors such as automotive batteries. Besides, EVs contribute to the smart people because EVs can promote creative ideas, industries, and people. Compared to conventional vehicles, EVs produce fewer emissions that affect climate change and smog for the smart environment.

\subsection{EV Charging Station}

Although the interest in EVs is rapidly rising nowadays, the idea of using electric propulsion for cars is not new. The first electric car was invented in the 1830 s, many years before the invention of gasoline and diesel engines. At the beginning of the 1900s, the number of automobiles using electricity was nearly two times more than the number powered by gasoline in the United States. However, in the 1920 s electric cars began to disappear due to the reasons such as range anxiety, the decline in the oil prices and innovations in the gasoline engines. Although the interest in the electric cars revived in the 1960s, most cars have been low-range neighborhood electric cars at that time. In the first decade of the 2000s, Tesla Motors launched the first highway electric car and in the following decade, car companies have been conducting R\&D activities on the efficiency improvement of electric cars.

Although there are different genres of EVs in the market, PEVs-collective of PHEVs and BEVsprovide a number of benefits to the environment. They reduce reliance on fossil fuels, which accounts for more than $90 \%$ of the total U.S. transportation energy consumption [3]. PEVs can serve as energy storage facilities to address grid demand response [2]. The PEV sales in the United States increased by $40 \%$ in 2016, reaching a total stock of 500,000 vehicles. Nevertheless, a widespread market adoption of PEVs remains hindered by many factors, such as the limited availability of models and styles, the higher cost compared with conventional vehicles, and the lack of convenient and ubiquitous network of charging stations [3]. Therefore, deploying widespread and efficient PEV charging stations is critical to promoting PEVs, alleviating range anxiety of drivers, and providing an opportunity for long-distance travel.

As an increased number of EVs enter the market, the buildout of proper charging infrastructure becomes critical. An EV charging station supplies electricity for the recharging of PEVs. The distance that an EV can travel relies on whether a facility for refueling exists when battery power dwindles [9]. Currently, three types of EV charging stations exist: (1) the Level 1 for residential homes, (2) the Level 2 for parking and public buildings, and (3) the Level 3 for DC fast charging stations. The Level 1 residential charging enables drivers to charge in their homes but it requires a long charging time and does not provide a long range. Drivers often prefer to charge quickly and conveniently on the road to avoid range anxiety [11]. The Level 2 charging is faster than Level 1 and provides more range per hour than Level 1 charging. As of 2015, approximately $70 \%$ of public EV charging outlets are of the Level 2 type, $21.5 \%$ are Level 1, and $8.5 \%$ are Level 3 [10]. Despite being the least-adopted charger type, the Level 3 charging, often termed fastcharging station, is able to charge a PEV battery up to $80 \%$ within minutes. The prime advantage of DC fast charging is that charge time is drastically reduced and adds 50-70 miles of range in approximately 20 
minutes [12]. Therefore, among the various types of charging, the Level 3 fast-charging stations are particularly required to boost EV sales and usage.

\subsection{Charging Infrastructure in the U.S.}

According to a report from the U.S. Department of Energy (DOE) [3], developing a U.S. network of nonresidential EV supply equipment (EVSE) that enables broader PEV adoption and maximizes PEV use. In the report, the National Renewable Energy Laboratory's (NREL's) Electric Vehicle Infrastructure Projection tool is used to estimate the non-residential charging requirements for a baseline scenario of 15 million PEVs on U.S. roads in 2030. Shortly, the estimation shows the bottom line of EV charging stations that need to be built and installed. The fast charging station estimation are obtained in two steps. The first step is to estimate the fast-charging station in cities and towns, and the second step is to estimate the fast charging station on interstate freeways to enable long-distance continued transportation.

The DC fast charging is advantageous for range and charging time. The DOE report highlights that at least 8,072 fast charging stations $(4,861$ in cities and 3,211 in towns) are required in the United States. The station density is applied to the 108,246 square miles occupied by cities and towns in the United States. Figure 1 displays the interstate corridor network. The thick red lines indicate the 70-mile-radius red buffer areas that would be served by the projected national EV charging infrastructure network.

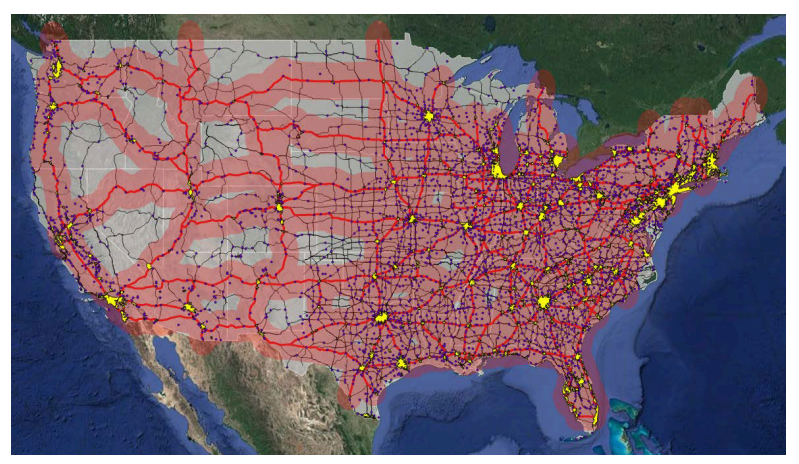

Figure 1 Estimated Charging Station Network in the U.S.

Scenarios used in the NREL's estimation do not consider the Level 1 charging although they assume most consumers prefer to charge at home. The Level 2 is assumed to be primarily used for charging within walking distance from a destination. The estimated consumer demand of the Level 2 charging is estimated at 600,000 plugs necessary to support 15 million PEVs (approximately 40 plugs per 1,000 PEVs). The estimated coverage assume the charging infrastructure is uniformly spaced on a square grid across a twodimensional area within each community. PEV drivers cannot be more than 3 linear miles from a charging station in a given city, 56 stations per 1,000 square miles would be required (for reference, there are currently 960 gasoline stations per 1,000 square miles in U.S. cities). For example, a case study of Columbus in the state of Ohio shows that PEV charging infrastructure in the Columbus area reduces range anxiety as a barrier to PEV sales and provides stakeholders guidelines to effectively invest PEV charging infrastructure, regardless of private and public resources [13].

\subsection{Battery Storage Technology}

As EVs gain traction, energy storage becomes a necessary component of urban infrastructure [14]. However, it is unclear whether and how battery storage can serve a crucial role in enabling charging stations to fulfill customer demand and be a profitable investment to charging station operators. Many options of battery storage technologies are available in the market. Each claims to be competitive in terms of safety, cost, and technical performance. Thus, the decision making of appropriate technology for a particular application is critical to the investors. Many factors are involved in assessing the optimal size of storage and the locations of charging stations that are suitable for deployment. An increasing need emerges asking for decision tools and data analytics that evaluate the costs, benefits, and values of a battery storage project within a given urban area [15].

However, little extant research has addressed the construction of battery storage technologies within a network of charging infrastructure. Deng, et al. [16] presented a method for creating high-power fastcharging batteries controllable using two energy storage units. But the study only addresses the energy regulation problem. Rogge, et al. [17] conducted an analysis using real-world bus network data in Germany and explained the tradeoff between battery capacity and charging power. The study does not consider the economic implications of employing energy storage units for that network. Ding, et al. [18] proposed a mixed-integer nonlinear programming formulation to extract the monetary value of energy storage used in coordination with charging infrastructure but the study does not apply the model to a real-time network of charging infrastructure to validate the model's reliability. Bashiri and Bahadori [19] presented a fast charging station with a flywheel energy storage system to meet demand charge, improve and develop the load 
profile, and minimize the operational costs of a fast charging station. Although they used a lifecycle cost analysis approach to comparing different storage systems, the operational costs of fast chargers were not discussed. Momtazpour, et al. [20] demonstrated a systematic data-mining method that can be used to identify locations for placing charging and storage infrastructure; but they did not consider some important measures such as battery life, energy storage, and economic performance. In summary, most studies do not integrate the battery storage system into the EV charging infrastructure's design and construction process.

\section{Data and Methods}

To address the aforementioned knowledge gap, we developed a discrete event simulation (DES) -based model to determine the battery storage for urban charging infrastructure. We applied the model to the Detroit area in the state of Michigan to explore the charging station network. The model is developed using Python programing language. Figure 2 displays the programming interface.

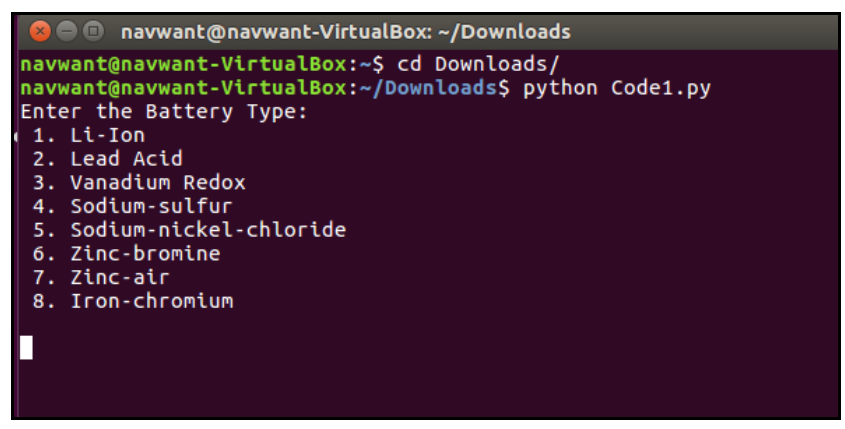

Figure 2 Programming Interface in Python

The model considers varying energy demand and different battery units. The installation cost range of each battery type and vendor are used as model inputs, and the model parameters (i.e., location and power output) are based on the geographic locations of a network of fast chargers in a given urban area. To address the energy gap of charging infrastructure, battery units are installed to supply energy to the nearby charging stations and exchange stored energy. The model evaluates the optimal configuration of battery units that are required to meet the energy demand for the whole network while containing the minimum cost. The configuration depends on the network structure such as the battery size, battery type, and energy exchange range.

\subsection{Discrete event simulation}

Technically, DES creates a system as a chronological sequence of events where each event can be defined as an instant in which a significant state change occurs in the system $[21,22]$. DES has been used to tackle a wide range of problems, including project planning [23, 24], optimization of construction operations [25], resource allocation $[25,26]$ and strategic construction management [27]. The fundamental components of DES are as follows:

- Entities - Entities are items that flow through the simulation [28].

- Events - Events are another major element of a DES. These are broadly defined as anything that can happen during the simulation [28]. The addition of each battery unit marks an event in the simulation.

- Time - Another major component of a DES is time. The simulation clock tracks the passage of time.

- Resources - A major element for economic evaluation is handling of resources, which are incorporated directly into a DES. An entity may consume a resource, and this consumption involves a defined number of resource units. In the model in this study, energy units are resources.

Most steps in the DES development procedure are common to all modeling approaches. First, formulate the problem and include the simulation goals [28]. The process of events is the crucial part for a DES program. This process is ideally to be completed using a generalpurpose programming language such as Fortran or Python. Both conduct the simulation by applying the given logic to each entity. The model is run until the system stabilizes to a steady state or a pre-specified condition.

\subsection{Monte Carlo simulation}

In a Monte Carlo simulation, each simulation run generates random numbers that determine whether an event occurs. We used scikit-monaco (v0.2.1), a library of Monte Carlo integration in Python, to complete the simulation. In this study, the lognormal distribution is used to simulate the cost value of power line network (e.g., a microgrid network). In contrast to a normal distribution that can take both positive and negative values, a lognormal distribution is widely used to represent the distribution of financial assets (e.g., good prices) as they cannot be negative [29].

\subsection{Modeling}


In the model, each charging station has two attributes: its geographic location, and a fixed demandsupply energy gap. The coordinates (i.e., the latitude and longitude values) are known for all 15 charging stations in the Detroit Area, Southeast Michigan (Figure 3). The energy demand-supply gap is assumed that every fast charging has a constant demand that is equal to the maximum rated power of that charging station. The supply range for each charging station is obtained from comments by EV drivers who use the charging stations. The energy demand-supply gap for a charging station is calculated by taking the difference in demand and minimum supply.

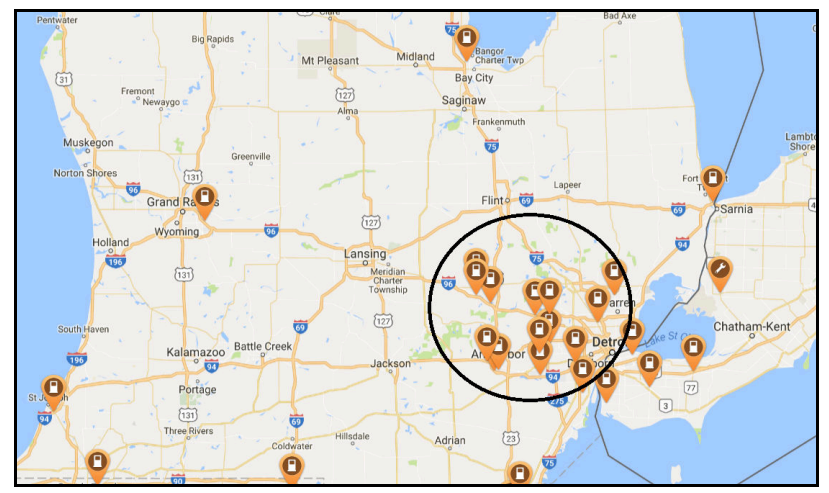

Figure 3 A Network of Charging Stations in the Detroit Area, Michigan.

Table 1 shows the inputs used in the model. The model considers the installation and construction costs of the battery storage system and the cost of setting up a new distribution line (grid cost) to enable the exchange of energy from batteries. The characteristics of the charging infrastructure network in Southeast Michigan are integrated into the input values based on which the model is developed. The integration is implemented in Python using the scikit-monaco library for Monte Carlo simulation.

Table 1. Inputs and Values

\begin{tabular}{|l|l|l|}
\hline \multicolumn{1}{|c|}{$\begin{array}{c}\text { Input } \\
\text { Category }\end{array}$} & \multicolumn{1}{|c|}{ Inputs } & \multicolumn{1}{c|}{ Input values } \\
\hline Battery & Battery type cost & See Table 2 \\
\cline { 2 - 3 } & Battery size & $(1-100) \mathrm{kW}$ \\
\hline Station & Location & $(\mathrm{x}, \mathrm{y})$ coordinates \\
\cline { 2 - 3 } & Demand gap & constant $(\mathrm{kW})$ \\
\hline Network & Exchange range & $(0.00-1)$ unit distance \\
\cline { 2 - 3 } & $\begin{array}{l}\text { New distribution } \\
\text { line cost }\end{array}$ & $\begin{array}{l}\$ 8,325,000 \text { per unit } \\
\text { distance }\end{array}$ \\
\hline
\end{tabular}

Table 2 shows the installation cost range of various battery types. The construction and network costs are fixed for all battery types. In the interface, user need to select the battery type. Based on the selected battery type, the installation cost range of that battery is chosen and converted into a lognormal distribution. Next, the model calculates total costs and selects 10,000 total cost values from a lognormal distribution. The model varies battery size from $1 \mathrm{~kW}$ to $100 \mathrm{~kW}$ in increments of $1 \mathrm{~kW}$ and the exchange radius varies from 0.00 to 1 in increments of 0.01 units. As a result, the simulation generates $100 * 100 * 10,000$ input points. The model then calculates the required number of batteries, battery size, and exchange range for all input points in an attempt to achieve the lowest cost. The researchers run the simulation model twice for every battery type: one considering the network cost and the other do not consider network costs. In the first case (i.e., considering network costs), new distribution lines are constructed within an existing microgrid network. In the second case (i.e., no network costs), all batteries and charging stations are connected to an existing microgrid network within new distribution lines.

Table 2. Battery Type and Cost

\begin{tabular}{|l|c|c|}
\hline \multicolumn{1}{|c|}{ Battery Type } & $\begin{array}{c}\text { Installation Cost } \\
(\mathbf{\$} / \mathbf{k W})\end{array}$ & $\begin{array}{c}\text { Construction } \\
\text { Cost } \mathbf{( \$ )}\end{array}$ \\
\hline Lithium-ion & $1,000-2,100$ & $\begin{array}{l}20,000 \text { per } \\
\text { installation }\end{array}$ \\
\hline Lead-acid & $500-2,500$ & $\begin{array}{l}20,000 \text { per } \\
\text { installation }\end{array}$ \\
\hline Vanadium redox & $800-1,100$ & $\begin{array}{l}20,000 \text { per } \\
\text { installation }\end{array}$ \\
\hline Sodium-sulfur & $500-600$ & $\begin{array}{l}20,000 \text { per } \\
\text { installation }\end{array}$ \\
\hline Sodium-nickel- \\
chloride & $700-1,200$ & $\begin{array}{l}20,000 \text { per } \\
\text { installation }\end{array}$ \\
\hline Zinc-bromine & $300-1,600$ & $\begin{array}{l}20,000 \text { per } \\
\text { installation }\end{array}$ \\
\hline Zinc-air & $200-300$ & $\begin{array}{l}20,000 \text { per } \\
\text { installation }\end{array}$ \\
\hline Iron-chromium & $300-500$ & $\begin{array}{l}20,000 \text { per } \\
\text { installation }\end{array}$ \\
\hline
\end{tabular}

The optimum network will meet the energy demand for all charging stations while reaching the lowest costs, as listed in Eq. 1.

$C t=C i+C c+C n$

where:

$C t=$ Total cost of energy supply

$C i=$ Installation cost

$C c=$ Construction cost

$C n=$ Network cost 


\section{Results}

Table 3 lists the simulation results of the battery storage system in the Detroit area. (1) Results show that the Li-ion battery storage systems has the highest total cost while the Zinc-air battery storage system has the lowest total cost when the energy exchange among stations occurs without new power lines. Regardless of battery type, the observed energy exchange range is less than 5 miles (i.e., 0.1 units). The finding indicates that a short range of energy exchange (radius $<5$ miles) is viable to reduce the overall costs. (2) Results also show that the battery size of $29 \mathrm{~kW}$ is desirable for most battery types. The size is smaller than expected given that the energy exchange does not need new grid lines. (3) Results show that the Zinc-air battery storage is an exemption. For the Zinc-air battery, a bigger size of $53 \mathrm{~kW}$ with a smaller number (i.e., 6 battery units) and a longer exchange range of 49 miles (i.e., 0.98 units) are desirable. The finding indicates that when the battery installation costs decrease, the battery storage system favors a few number of big battery units to meet a long-range of energy exchange. (4) Results show that the number of battery unit is consistently 10 units for most battery types except for the Li-ion (13 units) and Zinc-air (6 units). This finding indicates that least two-thirds of the 15 charging stations in the Detroit area need a battery storage system.

Table 3. Simulation Results

\begin{tabular}{|l|c|c|c|c|}
\hline \multicolumn{1}{|c|}{$\begin{array}{c}\text { Battery } \\
\text { Type }\end{array}$} & $\begin{array}{c}\text { Total } \\
\text { Cost } \mathbf{( \$ )}\end{array}$ & $\begin{array}{c}\text { Size } \\
\mathbf{( k W )}\end{array}$ & $\begin{array}{c}\text { Range } \\
\text { (units) }\end{array}$ & Number \\
\hline $\begin{array}{l}\text { Lithium- } \\
\text { ion }\end{array}$ & $4,218,274$ & 22 & 0.81 & 13 \\
\hline Lead-acid & $3,548,833$ & 29 & 0.67 & 10 \\
\hline $\begin{array}{l}\text { Vanadium } \\
\text { redox }\end{array}$ & $2,889,329$ & 29 & 0.36 & 10 \\
\hline $\begin{array}{l}\text { Sodium- } \\
\text { sulfur }\end{array}$ & $1,786,008$ & 29 & 0.36 & 10 \\
\hline $\begin{array}{l}\text { Sodium- } \\
\text { nickel- } \\
\text { chloride }\end{array}$ & $2,784,694$ & 29 & 0.73 & 10 \\
\hline $\begin{array}{l}\text { Zinc- } \\
\text { bromine }\end{array}$ & $2,323,296$ & 29 & 0.95 & 10 \\
\hline Zinc-air & 877,810 & 53 & 0.98 & 6 \\
\hline $\begin{array}{l}\text { Iron- } \\
\text { chromium }\end{array}$ & $1,295,707$ & 29 & 0.5 & 10 \\
\hline
\end{tabular}

Figure 4 visualizes the above findings, exhibiting the tradeoff of cost, battery size, and exchange range through 3D graphs. The graphs are obtained from the simulation results for each of the eight battery type.
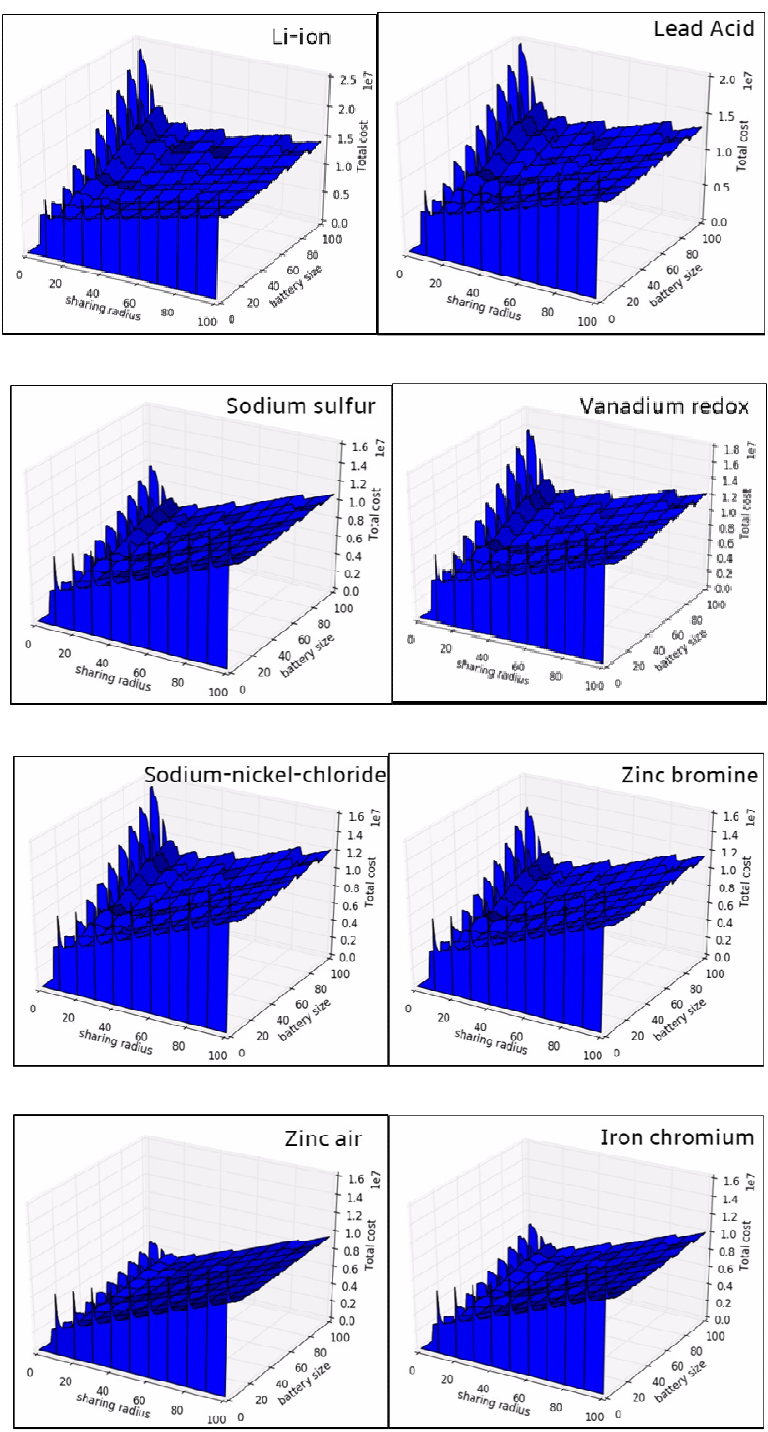

Figure 4. 3D graphs of Network by Battery Type

\section{Discussion and Conclusion}

This paper describes a DES model that is used to support the decision of the planning and design of a charging station network. In the network, battery storage units are introduced to address the energy supply and demand gap for fast charging stations. A case study of Detroit area in the southeast Michigan is used to demonstrate the model's usage with an attempt to achieve a zero gap in the energy storage. In such a network, an EV charging station within the battery storage system's range receives energy. The battery storage system provides a buffer to the charging station network. In this manner, the energy exchange can meet the energy demand for the whole charging station 
network using a small number of battery units. Findings show that, given the energy demand gap and the locations of the EV charging stations, the model can identify the optimum design of the battery storage system including the battery type, size, and exchange range that can result in the lowest total construction cost. This model provides a powerful decision support for planners, designers, and engineers when considering the construction of battery storage systems in smart cities.

The results from the case reveal many valuable factors and implications that help improve the design strategy of battery storage systems for a network of charging stations. (1) The construction cost of distribution lines are too high that, in this case, no energy exchange is feasible between the charging station and the battery storage system, regardless of battery type. (2) More than one battery unit is required for each $\mathrm{EV}$ charging station to address the whole network's demand when choosing a small battery size. (3) The battery storage system of a small number but a big size of battery units would lower the cost when only existing distribution lines are used. Overall, the coupling findings suggest that the battery storage systems largely benefit the condensed network of EV charging stations by supplying stored energy to the stations during peak hours and recharging battery units during off-peak hours.

In practice, the model can be applied to other urban areas to determine the battery size, number of units, and exchange range for reaching a decision of high cost-benefit investment. The information from the network cost help planners decide the best battery type for a given network of charging stations. In addition, the model is useful for EV charging station owners and operators when selecting vendors and contractors considering restrictions of the battery storage space, battery size and amount, and the overall cost. In a long run, the improvement of the EV charging infrastructure will ultimately contribute to the economic growth of automobile industry, the redevelopment of the nation's urban environment, and the well-being of people who are living in the U.S. cities and towns.

\section{Acknowledgment}

The work is partially supported by the Co-Learning Plan Program from the U.S. Economic Development Administration (EDA)'s University Center for Regional Economic Innovation (REI) at Michigan State University.

\section{References}

[1] V. Albino, U. Berardi, and R. M. Dangelico, "Smart cities: Definitions, dimensions, performance, and initiatives," Journal of Urban Technology, vol. 22, pp. 3-21, 2015.

[2] A. T. Radu, M. Eremia, and L. Toma, "Promoting battery energy storage systems to support electric vehicle charging strategies in smart grids," in Electric Vehicles International Conference (EV), 2017, 2017, pp. 1-6.

[4] E. D. T. Association. (2017). Electric drive sales dashboard. Available: http://electricdrive. org/index. Php

[3] E. W. Wood, C. L. Rames, M. Muratori, S. Srinivasa Raghavan, and M. W. Melaina, "National Plug-In Electric Vehicle Infrastructure Analysis," National Renewable Energy Laboratory (NREL), Golden, CO, USA, 2017.

[5] S. Negarestani, M. Fotuhi-Firuzabad, M. Rastegar, and A. Rajabi-Ghahnavieh, "Optimal sizing of storage system in a fast charging station for plug-in hybrid electric vehicles," IEEE Transactions on Transportation Electrification, vol. 2, pp. 443-453, 2016.

[6] I. Zubizarreta, A. Seravalli, and S. Arrizabalaga, "Smart city concept: What it is and what it should be," Journal of Urban Planning and Development, vol. 142, p. 04015005 , 2015.

[7] V. Fernandez-Anez, J. M. Fernández-Güell, and R. Giffinger, "Smart City implementation and discourses: An integrated conceptual model. The case of Vienna," Cities, 2017.

[8] B. W. Lane, N. Messer-Betts, D. Hartmann, S. Carley, R. M. Krause, and J. D. Graham, "Government promotion of the electric car: Risk management or industrial policy?" European Journal of Risk Regulation, vol. 4, pp. 227-245, 2013.

[9] Z. McDonald, "A Simple Guide to DC Fast Charging," Retrieved January, vol. 20, p. 2017, 2016.

[10] R. J. Flores, B. P. Shaffer, and J. Brouwer, "Electricity costs for an electric vehicle fueling station with Level 3 charging," Applied Energy, vol. 169, pp. 813-830, 2016.

[11] S. M. Sami, "Decision system for incremental upgrades of the Power Distribution System for Electric Vehicles," 2014.

[12] N. Thakur, "Effect of Battery Storage Technology on the Construction of Electric Vehicle Charging Stations," Michigan State University, 2017.

[13] E. Wood, C. Rames, M. Muratori, S. Raghavan, and S. Young, "Charging Electric Vehicles in Smart Cities: An EVIPro Analysis of Columbus, Ohio," National Renewable Energy Lab (NREL), Golden, CO, USA, 2018.

[14] B. Dunn, H. Kamath, and J.-M. Tarascon, "Electrical energy storage for the grid: a battery of choices," Science, vol. 334, pp. 928-935, 2011. 
[15] N. DiOrio, A. Dobos, and S. Janzou, "Economic analysis case studies of battery energy storage with SAM," National Renewable Energy Lab (NREL), Golden, CO, USA, 2015 .

[16] J. Deng, J. Shi, Y. Liu, and Y. Tang, "Application of a hybrid energy storage system in the fast charging station of electric vehicles," IET Generation, Transmission \& Distribution, vol. 10, pp. 1092-1097, 2016.

[17] M. Rogge, S. Wollny, and D. U. Sauer, "Fast charging battery buses for the electrification of urban public transport-a feasibility study focusing on charging infrastructure and energy storage requirements," Energies, vol. 8, pp. 4587-4606, 2015.

[18] H. Ding, Z. Hu, and Y. Song, "Value of the energy storage system in an electric bus fast charging station," Applied Energy, vol. 157, pp. 630-639, 2015.

[19] M. Bashiri and N. Bahadori, "Optimized plan of charging stations for management of demands: An emerging need of hybrid electric vehicle," in Future Technologies Conference (FTC), 2016, pp. 422-425.

[20] M. Momtazpour, P. Butler, N. Ramakrishnan, M. S. Hossain, M. C. Bozchalui, and R. Sharma, "Charging and storage infrastructure design for electric vehicles," ACM Transactions on Intelligent Systems and Technology (TIST), vol. 5, p. 42, 2014.

[21] J. Morecroft and S. Robinson, "Explaining puzzling dynamics: comparing the use of system dynamics and discrete-event simulation," in Proceedings of the 23rd International Conference of the System Dynamics Society, 2005, pp. 17-21.
[22] S. Robinson, Simulation: the practice of model development and use: Wiley Chichester, 2004.

[23] D.-E. Lee and D. Arditi, "Automated statistical analysis in stochastic project scheduling simulation," Journal of Construction Engineering and Management, vol. 132, pp. 268-277, 2006.

[24] J. Du, B.-C. Kim, and D. Zhao, "Cost Performance as a Stochastic Process: EAC Projection by Markov Chain Simulation," Journal of Construction Engineering and Management, vol. 142, p. 04016009, 2016.

[25] M. M. Hassan and S. Gruber, "Simulation of concrete paving operations on Interstate-74," Journal of Construction Engineering and Management, vol. 134, pp. 2-9, 2008.

[26] J. C. Martinez, "Methodology for conducting discreteevent simulation studies in construction engineering and management," Journal of Construction Engineering and Management, vol. 136, pp. 3-16, 2009.

[27] A. Alvanchi, S. Lee, and S. AbouRizk, "Modeling framework and architecture of hybrid system dynamics and discrete event simulation for construction," Computer-Aided Civil and Infrastructure Engineering, vol. 26, pp. 77-91, 2011.

[28] J. J. Caro, "Pharmacoeconomic analyses using discrete event simulation," Pharmacoeconomics, vol. 23, pp. 323-332, 2005.

[29] J. H. Gaddum, "Lognormal distributions," Nature, vol. 156, p. $463,1945$. 